\title{
O candomblé na Europa: fluxos e refluxos entre Brasil, Itália e Portugal
}

\section{Candomblé in Europe: flows and backflows between Brazil, Italy and Portugal}

\section{Tatiana Golfetto}

Itália. Universidade de Roma Sapienza. Doutora em História, Antropologia e Religiões pela Universidade de Roma Sapienza. ID ORCID: https://orcid.org/00o0-0002-8350-1278. E-mail: tatianagolfetto@gmail.com.

\section{Resumo}

Este artigo investiga a transnacionalização do candomblé na Europa a partir das relações entre os membros de uma mesma linhagem religiosa que se encontram no Brasil, na Itália e em Portugal. Utilizando-se do conceito de campo social transnacional, pretende evidenciar a circulação e a direção dos fluxos de bens materiais e simbólicos entre os países, que nos podem revelar dinâmicas e estratégias dos seus integrantes. Em seguida visa discutir as percepções desses membros em relação aos irmãos de santo e parentes de nacionalidades diferentes, percepções estas decorrentes das estadias e dos períodos de convivência, a fim de compreender os modos como esses integrantes constroem diferenças e semelhanças entre si.

Palavras-chave: Transnacionalização, Candomblé, Campo Social, Europa.

\section{Abstract}

This paper investigates the transnationalization of Candomble in Europe by analyzing the relations between members of the same religious lineage that live in Brazil, Italy and Portugal. Using the concept of transnational social field, it aims to highlight the circulation and direction of the flows of material and symbolic goods between these countries to reveal dynamics and strategies of.'

Recebido em 15 de novembro de 2019 
its members. Afterwards, it discusses the perceptions between members of different nationalities, in order to understand the ways in which these members build differences and similarities between them.

Keywords: Transnationalization, Candomblé, Social Field, Europe.

\section{INTRODUÇÃO}

Uma série de estudos recentes demonstram como a expansão das religiões brasileiras de matrizes africanas a outros países não tenha se limitado a contextos de fronteira como, por exemplo, a Argentina e o Uruguai, mas tenha chegado a regiões mais distantes como a Europa e até mesmo o Japão ${ }^{1}$. É possível enquadrar essa expansão em um contexto mais geral caracterizado pelo fenômeno da globalização. O desenvolvimento da tecnologia, dos meios de comunicação e de transporte de fato facilitaram e aceleraram o contato, a circulação de pessoas e as trocas de bens materiais e simbólicos entre os países do globo; ao mesmo tempo em que barreiras foram e são paradoxalmente criadas para impedir essa mesma circulação à uma parcela importante da população mundial, como acontece, por exemplo, com os refugiados que tentam chegar às costas europeias.

Apesar desses aspectos da globalização, muitas vezes contraditórios, caracterizarem o mundo contemporâneo, não é correto afirmar que a circulação de pessoas e ideias seja um fenômeno novo. Na Antiguidade, considerando, por exemplo, a extensão do Império Romano, regiões distantes do globo já interagiam e efetuavam trocas culturais e comerciais. Apesar disso, é a partir do final da Segunda Guerra Mundial e, mais visivelmente, a partir dos anos 1980, que as interações globais ganharam características inéditas. Piero Vereni (2012), na sua introdução ao volume italiano de Appadurai (2012), demonstra como as novidades desse processo dizem respeito à intensidade $\mathrm{e}$

\footnotetext{
Para contextos europeus, ver Pordeus Jr. (2009), que analisa as religiões afro-brasileiras em Portugal; Bahia (2013) para Alemanha e Suíça; e Teisenhoffer (2007) para a França. Para a umbanda no Japão, ver Arakaki (apud ROCHA E VÁSQUEZ, 2013, p. 249-270).
} 
extensão dessas interações, causando o que David Harvey definiu de "compressão espaço-temporal" (apud ROCHA; VÁSQUEZ, 2013, p. 19).

O uso generalizado do termo "globalização" para caracterizar qualquer relação e processo que atravesse as fronteiras de um Estado foi criticado por vários autores. Ulf Hannerz (2001, p. 9), por exemplo, propôs o uso do termo "transnacionalização" por considerá-lo mais "humilde" e mais adequado para definir os fenômenos que variam em termos de escala e distribuição. Citando T. Csordas, Argyriadis et al. (2013) também criticam o caráter geral e totalizante do termo e o consideram unidirecional. Nesse sentido, a direção dos fluxos culturais, por exemplo, e da influência partiriam somente de um centro ativo, globalizado e responsável pela produção cultural, como a Europa, e iriam em direção à periferia, considerada passiva e receptiva, como seria o caso da América Latina ou do continente africano. Contrariando essa lógica colonial, vários estudos demonstram, na verdade, uma multiplicação e a variedade de centros de produção cultural, relativizando assim a lógica centro-periferia. Além disso, relatam como a expansão das religiões e das práticas religiosas acontece em várias direções, do "Sul" ao "Norte" do mundo e inclusive entre um "Sul" e outro, por exemplo, entre a América Latina e a África (ARGYRIADIS; DE LA TORRE, 2013, p. 13). Esse papel ativo do "Sul", no qual o Brasil tem um dos lugares de destaque, demonstra como a cartografia religiosa do mundo contemporâneo é, na realidade, complexa, variada, marcada pela pluralidade religiosa e composta não só por diversos polos de produção cultural, mas também por diversas modalidades de circulação e consumo de práticas culturais e religiosas (ROCHA; VÁSQUEZ, 2013, p. 23). Além disso, é necessário considerar a diversidade dos atores responsáveis por esses processos, já que envolvem não somente atores institucionais, como Estados, mas também e, em alguns casos de maneira particular, indivíduos, pequenos ou grandes grupos, associações e empresas comerciais (HANNERZ, 2001).

Para tratar essa complexa realidade de maneira mais "humilde" é fundamental levar em consideração o fato de que as conexões culturais que transcendem as fronteiras de um país produzem efeitos em ambas as partes consideradas, ou seja, tanto no contexto de origem dessas práticas culturais ou 
religiosas, quanto no contexto de chegada. Em outras palavras, os processos de transnacionalização não são caracterizados por uma simples transposição de elementos culturais de um contexto a outro. A transnacionalização implica um duplo movimento: o desenraizamento ou o desalojamento de práticas culturais ou religiosas do seu contexto histórico e geográfico de origem e a sua subsequente localização, ou seja, a sua reinserção, apropriação e ressemantização no novo contexto nacional (FRIGERIO, 2013). Isso significa considerar em que modo os fenômenos e as circulações globais são vividos localmente. O termo "glocalização", proposto pelo sociólogo Roland Robertson (1992, p. 144), explicita exatamente essa relação dialética entre o global e o local e permite analisar o duplo efeito causado pelas dinâmicas de relocalização: a relocalização do global e a transnacionalização do local. Contra um caráter totalizante, é possível afirmar que essa perspectiva coloca em evidência as diferentes dinâmicas de intervenção humana (ARGYRIADIS; DE LA TORRE, 2013, p. 14), as estratégias, a agency dos atores para "conquistar" novos territórios, para adaptar, resistir, mudar ou manter certas práticas e reconfigurar a própria identidade em base a critérios diferentes daqueles nacionais ou hereditários.

Nesse sentido, tal perspectiva nos leva a repensar também, como sugeriu Levitt e Schiller (2004), o terreno no qual os processos sociais acontecem. Para além das estratégias de expansão, as apropriações e as ressignificações locais, é possível considerar a transnacionalização também sob o aspecto da criação de redes de interações sociais que ligam contextos ou países diferentes. O presente artigo se propõe a refletir exatamente sobre o aspecto relacional da transnacionalização, ou seja, a analisar as interações que se manifestam em comunidades de candomblé que ultrapassam as fronteiras nacionais e que ligam pessoas que se encontram em países diferentes².

Ao resumir as perspectivas adotadas pelos estudos sobre a transnacionalização, Frigerio (2013) afirma que, enquanto os estudiosos latino americanos

\footnotetext{
Apesar dos dados aqui presentes terem sido coletados durante o trabalho de campo para a tese de doutorado, o artigo é resultado de reflexões posteriores, em especial para a minha comunicação no congresso da Associação de Brasilianistas na Europa (Abre), realizado em Paris em setembro de 2019.
} 
e europeus preferiram focalizar suas análises nos processos acima descritos de desalojamento e de localização dos elementos religiosos em um novo contexto, os estudiosos norte-americanos adotaram uma segunda perspectiva, que considera esses processos como o estabelecimento de um campo social formado por conexões transnacionais. Tais perspectivas não são mutuamente excludentes e se caracterizam pelo fato de, conforme a perspectiva adotada, destacarem processos sociais diferentes. Em outras palavras, cada perspectiva enfatiza aspectos distintos da transnacionalização (FRIGERIO, 2013, p. 17).

Os estudos que analisam a transnacionalização das religiões afro-brasileiras nos seus mais variados contextos muitas vezes privilegiaram a primeira abordagem ${ }^{3}$. O presente artigo se propõe a demonstrar a existência de campos sociais transnacionais a fim de refletir sobre esses processos, partindo das observações sobre as interações dentro de uma linhagem de candomblé composta por membros que se encontram em três países diferentes: Brasil, Itália e Portugal. A expansão do candomblé produz laços entre contextos diferentes, criando a ideia de uma comunidade que transcende as fronteiras do próprio país e que supera certas diferenças em favor de uma causa comum constituída pelos valores religiosos compartilhados. Porém, é possível identificar também momentos em que tais diferenças se fazem presente, causando conflitos e tensões (BEM, 2008). Nesse contexto, se destacam jogos identitários ligados à pertença a uma nacionalidade diferente e que muitas vezem entram em jogo, ora criando identificação entre os membros da comunidade, ora criando diferenciação (BEM, 2008). Para além de um contexto de fronteira geográfica como aquele analisado por Bem (2008), é possível, seguindo também a proposta de Marc Augé (2015), repensar a fronteira, no nosso caso, simbólica. Com efeito, o fato de recusarmos um "nacionalismo metodológico" (LEVITT; SCHILLER, 2004, p. 1007), não nos leva a adotarmos, por outro lado, uma perspectiva relativista, na qual as fronteiras são canceladas e desaparecem completamente. Desse modo, veremos como as diferenças nacionais podem aparecer em determinadas situações (ALVES, 2012).

\footnotetext{
Pode-se citar, entre outros, Frigerio (2013), Pordeus Jr. (2009), Teisenhoffer (2007).
} 
Nesse sentido, o conceito de "campo social transnacional" elaborado por Levitt e Schiller (2004) parece ser o mais adequado para pensar de que modo pessoas de nacionalidades diferentes vivem tais interações, já que nos permitirá examinar tais interações enquanto constituintes de um conjunto no qual circulam, de maneira desigual, ideias e práticas. Além disso, Levitt e Schiller (2004), retomando Pierre Bourdieu, nos lembra de como as relações sociais são estruturadas pelo poder. É fundamental recordar, a esse respeito, que as relações no candomblé se dão dentro de uma rígida hierarquia religiosa, isto é, dentro de uma rede de relações de poder, o qual, por sua vez, é estreitamente relacionado ao conhecimento religioso.

O caso de estudo analisado é o da família de santo de Pai Taunderan. As viagens que o sacerdote realiza e as suas estadias anuais na Europa demonstram que sua função como pai de santo é caracterizada também por uma certa mobilidade. Além de cuidar do seu terreiro brasileiro localizado em Juquitiba (SP), Pai Taunderan abriu, já há alguns anos, uma filial portuguesa que se encontra hoje em Costa da Caparica, cidade perto de Lisboa. O pai de santo paulista também tem uma ligação especial com a Itália, onde morou por alguns anos e pela qual tem um imenso afeto, conforme fez questão de enfatizar durante as entrevistas. Consequentemente, nossa análise se concentrará nas relações entre as pessoas da sua linhagem que se encontram nesses três diferentes contextos. É necessário, contudo, entender primeiramente como essas redes de relações foram criadas. Por isso, partiremos da trajetória pessoal e religiosa de Pai Taunderan (cf. FALDINI, 2009).

\section{A FORMAÇÃO DAS REDES: A TRAJETÓRIA DE PAI TAUNDERAN}

O percurso espiritual de Pai Taunderan apresenta as dinâmicas de passagem de uma religião afro-brasileira a outra já relatadas por Prandi (1991), entre outros, e que começa com um primeiro contato quando jovem ${ }^{4} \mathrm{com}$

Taunderan nasceu em 1970. 
a umbanda, para em seguida passar ao candomblé angola, no seu caso em 1987, e então ao candomblé keto. Mesmo mudando de nação, Pai Taunderan decidiu manter a digina ${ }^{5}$ que recebeu na nação angola. O seu papel na difusão do candomblé já tinha sido previsto pelo pai de santo responsável pela sua iniciação:

Dai eu tomei sete anos em keto, meu sacerdote já me dizia que desde o princípio que ele teria me dado um nome muito forte porque eu ia expandir o nome da religião. Eu conheci um rapaz de Oxum, ele me trouxe pra Europa pra jogar búzios $[\ldots] .^{6}$

Os anos de 1990 representaram um período importante na vida de Taunderan. Em sua narrativa, conta ter conhecido um pai de santo chamado Marcus de Oxum que tinha um stand onde jogava búzios em um festival latino-americano na Itália ${ }^{7}$. Pai Marcus convidou Taunderan a acompanhá-lo e esse acabou se mudando para a Itália, onde arrumou diversos tipos de emprego. Taunderan oferecia também consultas de búzios e passou a gerir o stand que tinha sido de Marcus de $\mathrm{Oxum}^{8}$. O stand do festival atraía um grande número de clientes e assim Pai Taunderan pôde economizar uma soma em dinheiro. Além disso, foi nesse contexto que pai Taunderan conheceu seus primeiros filhos de santo "estrangeiros", incluindo Pai Mauro", o que, consequentemente, o levou a alargar a sua família de santo para além das fronteiras brasileiras. Esses primeiros filhos fizeram suas iniciações no Brasil. Graças às economias que pôde fazer enquanto esteve na Itália, Taunderan conseguiu comprar

5 É o nome que se recebe depois da feitura do santo no candomblé angola.

6 Entrevista realizada em 24 ago. 2014, durante o trabalho de campo para a minha tese de doutorado, no bairro de Casal Palocco, Roma, Itália.

7 Trata-se de um festival de cultura latino-americana que acontece durante os meses de verão na periferia de Milão. Atualmente se chama Milano Latin Festival.

${ }^{8}$ Pai Marcus de Oxum acabou cedendo, por motivos pessoais, seu stand no Festival Latinoamericano a Pai Taunderan. Atualmente, o stand é de Pai Odê, pai de santo brasileiro bastante ativo na Itália. Além de visitar o país todo ano para cuidar do seu stand, Pai Odê é o atual pai de santo de Mauro (ver nota 10).

9 Pai Mauro foi um dos primeiros filhos de santo italianos de Pai Taunderan e é o pai de santo de um dos terreiros de candomblé keto mais antigos da Itália, fundado em 1997 em Milão e depois transferido a Arborio (província de Vercelli). Em 2008, por causa de alguns desentendimentos, Mauro e Pai Taunderan romperam e Mauro passou a ser filho de Pai Odê. 
um terreno em Juquitiba (SP) e, assim, começou a construir, em 1997, a sua própria casa de santo. Antes disso, o pai exercitava a sua atividade sacerdotal, que incluía a realização de algumas iniciações, no terreiro de Pai Odê, localizado em São Paulo (SP).

Portanto, o período que esteve na Itália foi decisivo para Pai Taunderan, tanto para melhorar a sua qualidade de vida, como para impulsionar a sua carreira sacerdotal no Brasil. De um lado, com o dinheiro que conseguiu economizar, ele pôde abrir o seu próprio terreiro, ganhando assim autonomia, e ainda conseguiu construir a sua habitação pessoal. De outro, pôde aumentar o seu número de filhos de santo, alargando e diversificando a sua comunidade religiosa em termos de nacionalidade. Aolongo dos anos, Pai Taunderan iniciou também um peruano, um francês, alguns portugueses e espanhóis. A grande maioria desses filhos não abriu terreiros nos próprios países e esses frequentam como uma certa regularidade o terreiro brasileiro do pai. Mesmo depois que voltou ao Brasil, Taunderan continuou a ir à Itália pelo menos uma vez por ano, tanto para visitar e ajudar o seu então filho de santo Mauro, que, desde 1997, abrira um terreiro em Milão, como também para jogar búzios para uma série de clientes que o pai de santo brasileiro fez no período em que morava na Itália. Atualmente, Taunderan continua visitando o país todo ano e suas estadias geralmente duram dois ou três meses durante o verão europeu. Ele normalmente se hospeda na casa de seus filhos de santo italianos que têm terreiros no país. Os dois terreiros italianos ligados à sua família se encontram na periferia de Roma e têm como responsáveis mãe Viviana, em Ostia Antica, e Pai Giorgio, em Casal Palocco. Até 2017, existia uma outra casa de santo ligada à família de Taunderan localizada em Vigevano (província de Pavia) e da qual Pai Luca era responsável, mas essa foi fechada por motivos pessoais. Muitos filhos de santo de Luca acabaram dando as suas obrigações com Pai Taunderan e, por isso, viraram seus filhos de santo.

É interessante notar que a ligação com os dois sacerdotes romanos não começou durante as estadias italianas de Pai Taunderan. Segundo a narração de Viviana, ela conheceu Taunderan em 2005 através da internet, 
durante um período em que sofria com mal-estar e alergias, que começaram depois que o terreiro que frequentava em Ardea, cidade perto de Roma, fechou ${ }^{10}$. Viviana passava horas na internet à procura do seu pai biológico e, um dia, enquanto estava em casa com o seu então companheiro Giorgio, acabou achando o site de Pai Taunderan ${ }^{11}$. Viviana o contatou via e-mail e, em seguida, se falaram pelo telefone. Depois de alguns meses de conversação e aproveitando que Taunderan se encontrava na Europa, eles decidiram se conhecer pessoalmente. Taunderan foi à Roma e, a partir daí, iniciaram uma relação de amizade que levou, em seguida, Viviana e Giorgio a irem ao Brasil em 2009, onde fizeram o santo com Pai Taunderan. Em 2013, mãe Viviana abriu oficialmente a sua casa de santo, com a formação do primeiro grupo de filhos de santo, nos arredores de Roma. Em 2015, foi a vez de Giorgio fundar seu terreiro também nos arredores de Roma. Durante os anos em que não tinham uma casa de santo, ou quando essas estavam em construção, Viviana e Giorgio frequentaram, junto a um grupo de abiãs italianos que começava a se formar, o terreiro português de Taunderan, onde participaram de algumas cerimônias. Além disso, durante os períodos que passavam no terreiro do pai no Brasil tiveram a oportunidade de conhecer os filhos de santo portugueses de Taunderan, alguns dos quais com terreiro aberto em Portugal. A relação de amizade com esses portugueses foi importante para a constituição dos dois terreiros italianos, como veremos adiante.

Já a ligação de Taunderan com Portugal teve início no final da década de 1990, quando seu filho de santo português o convidou para ir ao país conhecer um grupo de pessoas que frequentava um terreiro de umbanda localizado a Alfeizerão, freguesia de Alcobaça, e que tinha ficado sem pai de santo depois do último ter morrido. Foi assim que Taunderan se tornou pai de santo de grande parte dessas pessoas, impondo uma mudança, utilizando suas palavras, "gradual" da umbanda ao candomblé. O terreiro se transferiu em 2001 a

\footnotetext{
${ }^{10}$ Apesar de frequentar esse terreiro, que organizava cerimônias de umbanda e de candomblé keto, Viviana não chegou a fazer o santo.

${ }^{11} \mathrm{O}$ site foi desativado e não existe mais.
} 
Macarca, perto de Nazaré, e, em 2008, para a Costa da Caparica, onde atualmente se encontra, quando Ana de Oxum, uma portuguesa, hoje mãe pequena do terreiro, presenteou Taunderan com a casa que viria a ser a filial portuguesa do seu terreiro de Juquitiba. Mãe Ana não fazia parte desse grupo de umbandistas e conhecera Taunderan através de um amigo em comum. Em um período em que tinha dores de cabeça incuráveis, Ana seguiu o conselho desse amigo e contatou Taunderan, o qual teria descoberto, através do jogo de búzios, as causas espirituais dessas dores. Ana decidiu assim ir ao Brasil se iniciar. Curada, resolveu que deveria presentear Taunderan com um lugar, onde o pai pudesse acomodar o seu nascente grupo de filhos portugueses e fundar uma filial do seu terreiro em território português. Atualmente, mãe Ana é a responsável por administrar e cuidar do terreiro na ausência de Taunderan. A casa de santo representa um ponto de referência importante para os filhos europeus do pai. Muitos deles se iniciaram ou deram suas obrigações ali, ao invés de irem ao Brasil, já que a distância e os custos da passagem aérea são evidentemente menores. Além do terreiro de Pai Taunderan, é importante citar, em tal contexto, os de seus filhos que fundaram casas de santo, como Pai Okoniba, português proprietário de um terreiro que também se encontra nos arredores de Lisboa. Durante uma de suas estadias brasileiras, Okoniba conheceu mãe Viviana e, a partir daí, ambos passaram a se visitar e participar de festas nos seus terreiros. Alguns filhos de santo brasileiros de Taunderan migraram para Portugal como Selma de Iemanjá. Seu marido, Pai Danilo, possui um terreiro na Costa da Caparica e ambos frequentam as casas de santo ligadas à família de Taunderan, tanto em Portugal como na Itália, e recebem esses parentes nas suas festas.

Em síntese, podemos afirmar que a trajetória de Pai Taunderan é caracterizada pela mobilidade. Desde os anos de 1990 até os dias de hoje, a sua atividade como pai de santo é marcada por idas e vindas entre o Brasil e a Europa, viagens durante as quais o pai de santo cuida do seu terreiro europeu, ajuda e participa de cerimônias nas casas de seus filhos e joga búzios para uma série de clientes. Essa mobilidade revela como a expansão das religiões afro-brasileiras na Europa nem sempre se dá através de migrações definitivas, apesar da 
distância que separa os dois contextos. Os sacerdotes podem viajar anualmente, mantendo terreiros nos dois continentes, assim como contato regular com membros da sua linhagem nos vários países em que atua. Taunderan conversa regularmente com seus filhos europeus através de dois grupos de WhatsApp, nos quais os membros dão recados, combinam estadias e trocam informações que dizem respeito à realização das atividades religiosas nos respectivos países.

\section{AS INTERAÇÕES ENTRE BRASILEIROS, ITALIANOS E PORTUGUESES}

A trajetória de Pai Taunderan revela a formação de redes que ligam o Brasil, a Itália e Portugal. As pessoas que fazem parte dessas redes têm a consciência, em maior ou menor grau, de pertencer a uma comunidade que ultrapassa as fronteiras do próprio terreiro e do próprio país. Apesar disso, nem todos os membros da família experimentam viver "transnacionalmente", ou seja, simultaneamente dentro e fora das fronteiras do próprio país. A presente seção partirá do conceito de "campo social transnacional" para tratar das relações entre os membros da família de santo de Pai Taunderan. Na verdade, se concentrará nos membros da sua linhagem religiosa, já que levará em consideração as relações com seus filhos de santo que fundaram terreiros nos seus respectivos países. Nesse sentido, pretende-se concentrar no impacto que essas relações transnacionais diretas ou indiretas produzem para os, em particular para aqueles que podemos chamar de agentes nodais, ou seja, indivíduos através dos quais as informações e os recursos fluem e que, no nosso caso, são representados pelos pais e mães de santo da linhagem indivíduos (LEVITT; SCHILLER, 2004).

As relações em uma família de santo são marcadas por princípios fundamentais do candomblé como a união, o respeito aos mais velhos e a colaboração, o que não as isenta em determinados momentos de conflitos e tensões, como demonstrou Vallado (2010). No processo de transnacionalização do candomblé, no qual pessoas e lugares distantes entram em contato, outros elementos se 
somam a essas dinâmicas como, por exemplo, as diferenças culturais e as percepções dessas diferenças por parte dos membros da família. Mas em que momentos tais diferenças são, ou não, percebidas? O que essas dinâmicas relacionais revelam? A fim de analisar essas questões, utilizaremos como ponto de partida o conceito de campo social transnacional, elaborado pelas antropólogas Peggy Levitt Nina Glick Schiller (2004) no campo dos estudos sobre as migrações a partir do conceito de campo de Pierre Bourdieu (2010).

A definição de Bourdieu (2010) não inclui a noção de campo social transnacional, já que o sociólogo francês não discute as implicações de campos sociais que não se restringem às fronteiras de um Estado (LEVITT; SCHILLER, 2004). A noção de campo social transnacional pode ser definida como "um conjunto de múltiplas redes de relações sociais interligadas, através do qual ideias, práticas e recursos são desigualmente trocados, organizados e transformados" (LEVITT; SCHILLER, 2004, p. 1009, tradução e grifo meus). É importante observar que, ao utilizar tal conceito, as autoras (LEVITT; SCHILLER, 2004, p. 1010, tradução minha) propõe também uma distinção entre o que chamou de "ways of being", ou seja, maneiras de estar no campo, que se referem às "relações sociais efetivas, às práticas reais nas quais os indivíduos se envolvem, mais do que às identidades associadas às próprias ações" e "ways of belonging", ou jeitos de pertencer ao campo, que se referem às práticas que sinalizam uma conexão consciente à um grupo em particular ou, no caso, ao campo. As antropólogas dizem (LEVITT; SCHILLER, 2004, p. 1010, tradução minha), em respeito às "ways of belonging" que "essas ações não são ações simbólicas, mas sim concretas, que marcam a pertença”. Desse modo, há uma distinção entre a existência de redes sociais, que no caso são transnacionais e a consciência de se estar inserido nelas.

Existem, então, diferentes modos de se estar em um campo social transnacional e de ser influenciado por esse. É através dos participantes, ou seja, dos agentes nodais do campo que as informações e os recursos fluem através das fronteiras ${ }^{12}$. No caso analisado, os agentes são representados pelos pais e mães

\footnotetext{
${ }^{12}$ Apesar de considerar, nesse artigo, agentes nodais somente os pais e mães de santo da família, é importante notar que outros membros, em determinados momentos, podem se comportar como tal, quando,
} 
de santo da família: Pai Taunderan, que é o vértice dessa linhagem, mãe Viviana e Pai Giorgio, os dois sacerdotes italianos ${ }^{13}$, mãe Ana, responsável pelo terreiro português do pai e Pai Okoniba. Eles mantêm um contato mais frequente entre eles, principalmente depois da criação dos grupos de WhatsApp, porque são filhos de santo diretos de Taunderan e ocupam uma posição importante, já que são os responsáveis pelas casas de santo pertencentes à linhagem.

Isso não quer dizer que os demais candomblecistas que vivem nos três países não ajam dentro do campo, não estejam inseridos ou não sejam influenciados por esse, o que vai depender do período, da situação ou do contexto. Por exemplo, alguns filhos de santo italianos vão, com uma certa regularidade, ao Brasil ou à Portugal para participar de cerimônias nos terreiros da família, entrando em contato, assim, com parentes religiosos de outras nacionalidades, o que é feito também pelos filhos portugueses. Nas viagens anuais que realiza à Europa, Pai Taunderan é geralmente acompanhado por outros brasileiros ligados à família como, por exemplo, sua filha e ekedi ${ }^{14} \mathrm{do}$ seu terreiro brasileiro, Crislene de Iemanjá; Pai Alá, seu pai de santo, que também tem um terreiro em Juquitiba (SP); ou filhos de santo brasileiros que, além de participarem e ajudarem na realização das cerimônias nos terreiros europeus, como veremos adiante, aproveitam a viagem para fazer turismo. É fundamental citar também, a esse respeito, a importância da internet e das redes sociais ${ }^{15}$, que permitem um contato e uma aproximação maior entre membros da família que se encontram em países diferentes, o que é demonstrado pelas várias mensagens, curtidas e comentários deixados nas fotos e nos perfis de Facebook e Instagram. Filhos de santo de Taunderan, que moram em Portugal ou na Itália, também

por exemplo, algum filho de santo compartilha, em um grupo de WhatsApp da casa de santo ou durante os momentos de convívio, alguma informação ou mito que encontrou na internet, sendo o responsável, portanto, da circulação de informações.

${ }_{13}$ No contexto italiano atual existem quatro terreiros de candomblé, sendo que dois deles fazem parte da família de santo de Taunderan.

${ }^{14}$ Ekedi ou equede é um cargo feminino que, entre outras funções, tem a responsabilidade de zelar pelo orixá quando esse está incorporado em uma filha ou um filho de santo.

${ }_{15}$ A internet e as redes sociais permitem ainda o contato com pessoas de fora da família de santo e da própria linhagem e servem, em alguns casos, para encontrar informações e imagens relacionadas às religiões afro-brasileiras. Para considerações sobre os usos da internet e das redes sociais por parte dos membros da linhagem, ver Golfetto (2017). 
circulam por esses terreiros. É possível notar que, dependendo do momento ou do contexto, mesmo aqueles que não têm uma vivência transnacional ou que não viajam possam conviver com "estrangeiros" no terreiro e consequentemente podem pensar a família de santo, e a sua religião, para além das próprias fronteiras geográficas. Assim, podemos observar as diferentes posições que uma pessoa pode ocupar dentro do campo social, o qual não se restringe aos agentes nodais. Ao pertencer a um mesmo campo social transnacional, essas pessoas se mantém conectadas, informadas umas das outras e podem agir no campo, mesmo não sendo agentes nodais, se algum acontecimento as levar a isso (LEVITT; SCHILLER, 2004).

Uma vez definidos os participantes que formam o campo social transnacional, devemos analisar as relações entre eles. Frigerio (2013) também utilizou esse conceito ${ }^{16}$ ao examinar a transnacionalização das religiões afro-brasileiras no contexto argentino. A esse fim, o autor (FRIGERIO, 2013) identificou a existência principalmente de dois campos sociais transnacionais presentes no país, formados por redes de linhagens religiosas e com dois eixos diferentes: um ligado a uma "tradição" uruguaia e o outro ligado a terreiros do Sul brasileiro, precisamente do Rio Grande do Sul ${ }^{17}$. Concentrou-se então nas relações entre esses dois campos, indicando um crescimento maior no número de terreiros do campo da "tradição" uruguaia. Diferentemente, nós nos focalizaremos nas relações e nas experiências dentro de uma mesma linhagem religiosa, ou seja, utilizando o conceito de campo social transnacional em uma escala menor e ressaltando assim outras dinâmicas.

Os momentos de convivência direta e de sociabilidade entre os membros da linhagem revelam algumas delas. A frequência das viagens e dos encontros que acontecem nos três países considerados dependem

\footnotetext{
${ }^{16}$ Nesse caso, Frigerio (2013, p. 18) prefere utilizar a palavra "transnacionalismo", ao invés de "transnacionalização", para destacar a diferença entre as duas perspectivas; este dá a ideia de ação e movimento, destacando os processos em que a religião se desloca de um contexto a outro; enquanto que o substantivo "transnacionalismo" remete à criação de uma entidade, no caso, o campo social transnacional. Eu utilizo "transnacionalização" para manter a ideia de movimento e enfatizar os fluxos, as trocas, os deslocamentos que acontecem dentro do campo.

17 No caso argentino analisado por Frigerio (2013) não se trata de candomblé, mas sim do batuque e da umbanda.
} 
claramente de uma série de fatores como, por exemplo, da disponibilidade econômica de cada membro ou da relação de proximidade existente entre os parentes religiosos. Os encontros que acontecem na Europa, ou seja, na Itália e em Portugal, coincidem, em grande medida, com as estadias anuais de Pai Taunderan, embora tenhamos notado algumas ocasiões em que os filhos italianos e portugueses da família tenham se encontrado sem a presença do pai.

Durante as suas estadias, Taunderan realiza algumas festas e obrigações no seu terreiro português. Quando está em Portugal, o pai aproveita também para visitar e participar de festas em outras casas ligadas à sua família, o que é documentado pelas fotos compartilhadas nos perfis de Facebook dos sacerdotes dessas casas. Já na Itália, além de participar das cerimônias, o pai ajuda na realização das iniciações e obrigações, que se concentram no período em que ele se encontra no país, fato que tenderá a mudar no decorrer dos anos. É importante ressaltar, como vimos na seção anterior, que os dois terreiros italianos, e principalmente em relação ao restante da família, são de recente fundação. Por isso, a ajuda e os ensinamentos do pai para se aprender, por exemplo, como fazer o santo a cada orixá eram, e ainda são em alguma medida, essenciais. É evidente que atualmente eles já têm um grau de autonomia e realizam obrigações e feituras sozinhos, mas o pai continua a ir e, se preciso, a ajudar. É importante notar que nos primeiros anos de fundação, e encontrando-se em um contexto completamente novo, esses terreiros não possuíam o quadro de cargos completo, ou seja, faltavam pessoas nessas casas com experiência e conhecimento para exercerem certas funções, principalmente durante períodos importantes, como a feitura de um santo ou uma obrigação. Apesar de quase todos superados, um problema, por exemplo, ainda persiste: a dificuldade de encontrar pessoas que saibam tocar os atabaques. As casas italianas têm alabês, mas não o suficiente para todos os atabaques. Durante o ano, outros ogãs exercem essa função, mas durante o período de feituras e obrigações faltam pessoas que conheçam os ritmos e as cantigas necessárias. Nessas ocasiões, alabês dos terreiros portugueses ligados à família, geralmente de nacionalidade brasileira, vão à Itália para tocarem os atabaques durante as festas. 
Além disso, é importante destacar a ajuda dos irmãos de santo portugueses e brasileiros, em especial os que são pais de santo em Portugal, na realização das iniciações e obrigações nos terreiros italianos durante os primeiros anos de fundação. Sendo um período caracterizado por um volume de trabalho muito grande, e faltando pessoas com experiência, esses parentes portugueses e brasileiros deram uma ajuda fundamental nas feituras e na realização dessas cerimônias e, desse modo, na consolidação dessa nova realidade.

Por outro lado, durante esses anos, os sacerdotes italianos, acompanhados de seus filhos e de seus abiãs, foram e ainda vão, com uma certa regularidade, à Portugal para participarem de festas nos terreiros da linhagem. Antes da iniciação do seu primeiro barco, mãe Viviana, por exemplo, foi à Portugal acompanhada do seu primeiro grupo de abiãs que fariam o santo em Roma, para participar de uma festa realizada em um terreiro da linhagem. Como esses abiãs nunca tinham participado de uma festa de candomblé, essa viagem deu a possibilidade a eles de terem um primeiro contato com o cotidiano de uma casa de santo. Por ser mais econômico e mais perto, alguns filhos europeus de Taunderan decidem fazer suas obrigações rituais durante as estadias do pai no terreiro português, ao invés de irem ao Brasil. Assim, o terreiro português demonstra ser um ponto de apoio importante para os filhos de santo europeus de Pai Taunderan.

Além da importância relativa à colaboração e à amizade entre irmãos portugueses, brasileiros e italianos, nota-se que esses momentos de sociabilidade e de convivência direta reforçam a identidade e os laços de parentesco religioso. Durante essas viagens, os irmãos de santo vivem momentos de convívio cotidiano, ficando hospedados na casa de seus parentes religiosos e compartilhando, desse modo, não só os espaços, mas também experiências dentro e fora do terreiro. São organizados, por exemplo, passeios turísticos aos monumentos de Roma e de Lisboa, almoços e jantares em restaurantes locais. São ocasiões em que se reforçam as amizades e em que se tem a oportunidade de conhecer outros candomblecistas no país e de ser convidados a festas em outros terreiros, ampliando, assim, as redes pessoais. É importante notar que ser convidado a uma festa, receber ou ir visitar um irmão de santo em 
outro país, assim como ter uma rede de conhecidos ampla representam grandes fatores de prestígio.

É evidente que podem surgir algumas tensões que, de maneira geral, se dão em momentos em que se critica algum comportamento ou em momentos em que "modos de fazer" diferentes entram em contato. De maneira geral, são feitos comentários, às vezes em forma de conselho à pessoa interessada, outras em forma de fofoca, que se relacionam a determinados comportamentos que são interpretados como "não ortodoxos" ou que não respeitam a lei do santo. Também podem surgir alguns comentários em relação, por exemplo, a modos de se cantar uma cantiga, de dançar, de preparar uma oferenda, ou seja, ao modo que se julga "correto" de praticar o candomblé. Os comentários ou as fofocas representam tentativas de se regular a prática do candomblé em um contexto internacional. Vimos como geralmente são feitos durante situações caracterizadas por trocas ou transferências de conhecimento religioso. Os conflitos decorrentes desses comentários ou fofocas revelam também jogos de legitimação entre os três contextos presentes na análise, ou seja, Brasil, Portugal e Itália.

Um outro tipo de cooperação entre os irmãos de santo é na esfera econômica e se refere ao custo da passagem aérea de Pai Taunderan para as suas estadias na Europa. De maneira geral, se tem o entendimento que o pai vai ajudar no crescimento dessas casas e, assim, os membros dos terreiros italianos e da filial do seu terreiro português se organizam para juntar a quantia necessária e lhe oferecer a passagem. Mas, nesse caso, podem surgir problemas ligados ao fato dos irmãos se encontrarem em países diferentes. As questões principais são: Com quanto cada um deve colaborar? Qual destino comprar? Brasil-Itália ou Brasil-Portugal? Como Pai Taunderan passa mais tempo na Itália, o destino final na maioria das vezes acaba sendo esse país.

Existe, ademais, uma circulação de objetos e de revistas relacionadas ao candomblé entre os três países. Na Itália, existem poucas lojas onde se pode encontrar o quanto necessário para os rituais e a prática do candomblé ou da umbanda. Algumas lojas exotéricas vendem poucos itens como, por exemplo, 
peneiras para jogar búzios, velas, estátuas de entidades da umbanda. Os italianos também frequentam o que se chama no país de "mercados étnicos", ou seja, mercados onde os migrantes, geralmente provenientes de países africanos ou asiáticos, vendem produtos, verduras, frutas e outros alimentos ligados ao seu país de origem. Os candomblecistas italianos compram, por exemplo, algumas ervas e ingredientes necessários para as oferendas - impossíveis de se encontrar nos supermercados italianos - e tecidos dos vendedores africanos para confeccionar roupas de orixá, panos de cabeça e panos da costa e para a decoração do terreiro. Pai Taunderan também aprecia esses tecidos e geralmente visita esses mercados quando se encontra no país. É interessante notar que a cortina do barracão do seu terreiro em Juquitiba é feita com um dos tecidos que comprou nesses mercados italianos. Como Portugal apresenta uma realidade afro-brasileira mais consolidada ${ }^{18}$, existe no país uma maior variedade de opções, com preços mais acessíveis. Alguns italianos aproveitam a estadia no país para comprar o necessário. É importante lembrar também que alguns brasileiros que fazem parte da comitiva de Pai Taunderan levam na mala muitas roupas e paramentos de orixás, entre outros objetos, para vender aos seus parentes europeus, em especial aos italianos, o que acaba sendo um meio para eles custearem a viagem para a Europa.

Por fim, é importante considerar, quando se trata de relações entre membros de uma linhagem religiosa de maneira geral, que aquelas entre filhos que se tornaram pais ou mães de santo podem ser marcadas por algumas disputas que se referem à uma relação mais próxima com o "vértice" da família. Ter uma relação privilegiada com o próprio pai de santo pode trazer algumas vantagens como, por exemplo, contar com a sua presença durante as cerimônias públicas organizadas nos próprios terreiros, ou até mesmo obter cargos importantes no terreiro desse vértice, demonstrando assim ao restante da família e ao povo de santo a confiança que o pai deposita naquele filho e o prestígio daquele terreiro. Essa relação privilegiada depende claramente de uma série de fatores, entre os quais a afinidade e as relações pessoais, que também têm um papel importante.

\footnotetext{
${ }_{18}$ Para o contexto português ver, entre outros, Bahia (2015), Dias (2014) e Pordeus Jr. (2009).
} 
As dinâmicas acima relatadas revelam a variedade de trocas, ou de fluxos, para utilizar uma das palavras chave sugeridas por Hannerz (1997), entre os membros da família que se encontram em países diferentes. Como vimos, esses podem ser de tipo econômico, de conhecimento religioso, de tipo material e a intensidade e a extensão desses fluxos podem variar de acordo com a situação. Além de fluírem de maneira desigual (LEVITT; SCHILLER, 2004), a direção desses fluxos, importante fator a se considerar, também pode variar dependendo da situação ou do o que é considerado. Assim, os fluxos não partem somente do Brasil para a Europa, mas existe uma circulação entre os três pontos: Brasil, Itália e Portugal. Desse modo, por exemplo, em determinada situação, como nos primeiros anos de fundação dos terreiros italianos, o fluxo de conhecimento religioso pode ir de Portugal à Itália.

É necessário levar em consideração um último aspecto. Em relação ao conceito de campo social, Levitt e Schiller (2004) ainda destacam, retomando Bourdieu (2010), como as interações sociais são estruturadas pelo poder. Assim, o campo em si é criado pelos participantes que se unem e lutam de algum modo por posições. Bourdieu (2010) define essa luta como uma luta simbólica entre os participantes, uma luta por prestígio ou para impor a própria visão no campo; segundo o sociólogo francês, os instrumentos utilizados pelos agentes do campo para participarem dessas lutas seriam os capitais que esses agentes possuem. O que a direção dos fluxos econômicos, de conhecimento religioso e assim por diante podem revelar é um utilizo desses capitais? O capital cultural - no caso o saber religioso -, o capital econômico e o capital social podem ser acionados para se criar prestígio. De fato, Bourdieu (2010) demonstra como o campo contribui para a formação de capital, ao mesmo tempo que esse modifica algumas relações de força presentes no campo. É evidente que, ao se levar em conta a hierarquia religiosa, o vértice da linhagem não entra nessas relações de força e a sua busca por prestígio se dá em um nível macro, ou seja, fora da família, entre o povo de santo em geral. Mesmo assim, considerando os outros participantes, dentro do campo social podem ser produzidos 
capitais para um reconhecimento social que passa obviamente pelo conhecimento religioso, mas que pode passar também pela relação pessoal com o vértice da linhagem.

\section{IRMÃOS DE ALÉM MAR: ESTADIAS DOS EUROPEUS NO BRASIL}

Os momentos de convivência entre os membros da família de santo revelam, como vimos anteriormente, fluxos de bens materiais e simbólicos que caracterizam o campo social transnacional. É evidente que nessas redes o contato mais frequente dos membros europeus da família seja com Pai Taunderan. Entretanto, muitos deles foram e vão ao Brasil com uma certa frequência, seja para realizar as próprias obrigações rituais, seja para participar de festas no terreiro de Pai Taunderan e de outras casas ligadas à família. É importante notar que, para além dos usos da internet e das redes sociais, são durante essas estadias, tanto no Brasil quanto na Europa, que os membros que não partem, têm a ocasião de conviver com parentes "estrangeiros" e de pensar a própria família de santo para além das fronteiras. Nessa seção, trataremos das estadias dos membros europeus no Brasil a fim de observar as percepções e as interpretações das diferenças e semelhanças, tanto por parte dos brasileiros quanto dos europeus.

As estadias dos membros europeus no terreiro localizado em Juquitiba (SP) dependem dos fatores já assinalados em precedência, ou seja, com frequência e duração que dependem da disponibilidade econômica e de tempo de cada membro. Para além das incompreensões que podem surgir por causa de diferenças culturais como a falta de conhecimento da língua portuguesa, no caso dos italianos e dos não lusófonos, ou dos costumes locais. O que se apresenta é uma situação decorrente dos modos de frequentação do terreiro, do convívio temporário com seus irmãos e parentes brasileiros. Esses filhos frequentam esporadicamente a casa, ou seja, têm uma relação com os irmãos brasileiros diferente de uma relação de convivência mais próxima, que muitas vezes 
caracterizam esses contextos. A inserção na comunidade se apresenta ainda mais complicado no caso de um filho europeu decidir fazer o santo no Brasil, geralmente sem ter uma experiência prévia no terreiro como abiã, já que esse iniciante precisa aprender muito mais rápido as regras e as dinâmicas dentro de uma casa de santo.

Em diversos relatos dos filhos europeus, a palavra desconfiança (por parte dos brasileiros) é utilizada para descrever os primeiros contatos com esses irmãos. Os brasileiros estariam acostumados a uma comunidade composta por um círculo restrito de pessoas, de nacionalidade exclusivamente brasileira, em qual quase todos se conheciam. A mudança na composição da família de santo é uma consequência da transnacionalização do candomblé e das outras religiões afro-brasileiras. A expansão dessas religiões cria um grupo de membros "não usuais", multicultural, com hábitos, culturas e costumes diferentes e que frequenta, quando o faz, esporadicamente o terreiro. Esses irmãos são considerados "diferentes" e é interessante citar um trecho da entrevista com Pai Taunderan que ilustra essa percepção:

A única coisa que meus filhos de santo sabiam que eles não eram brasileiros é que toda vez eles iam no banheiro com uma beauty case, então meus filhos riam, falavam assim "olha, aquele é estrangeiro pai, porque ele tá levando aquele beauty case pro banheiro", então quer dizer os meus filhos riam porque não é um hábito brasileiro ${ }^{19}$.

Pode-se então observar que, durante a convivência no terreiro, os brasileiros assinalaram elementos culturais, nesse caso representado por hábitos diferentes, em específico o uso de um objeto como o beauty case, como um elemento de demarcação, de diferenciação em relação àquele grupo de irmãos “não usuais". As diferenças culturais são percebidas também, em maior ou menor medida, como diferenças religiosas. Tanto os membros brasileiros quanto europeus percebem diferenças entre eles, as quais aparecem nos discursos de várias maneiras, como veremos a seguir.

${ }_{19}$ Entrevista realizada em 24 ago. 2014, em Casal Palocco, Roma, Itália. 
Os membros europeus da família veem o Brasil como o lugar de origem do candomblé. Como acontece também nesse contexto (CASTILLO, 2008), alguns desses membros, além de frequentarem os terreiros, procuram informações sobre a religião em livros e páginas da internet que estão, em sua grande maioria, em português. Os não lusófonos não podem contar com a vantagem de compartilhar a língua ${ }^{20}$ e acabam, segundo eles, perdendo muito tempo traduzindo textos com o auxílio do Google Tradutor. Poucos dentre eles falam português. Também por ser o lugar de origem, o candomblé seria uma religião extremamente difundida na sociedade brasileira. Segundo os europeus, o candomblé “aparece na televisão" e "é vivido todos os dias no Brasil", diferentemente do que aconteceria na Europa, onde "fora do terreiro é um outro mundo". O candomblé seria assim conhecido e praticado por quase todos os brasileiros, e essa difusão facilitaria a compreensão dos seus rituais e elementos religiosos por parte desses brasileiros. É importante lembrar que, se, por um lado, os elementos afro-brasileiros e afro-religiosos são parte integrante e fundamental da cultura brasileira, por outro lado, o percentual de pessoas no Brasil que se identificam como pertencentes às religiões de matriz africana dista muito da maioria da população ${ }^{21}$.

Além disso, segundo a percepção de alguns desses europeus, os brasileiros acham que o candomblé feito na Europa é muito diferente do brasileiro, isso seria consequência do fato desses brasileiros, por diversos motivos, não poderem ir à Europa ver como o candomblé é realmente feito nesse contexto. São durante situações de convivência e de sociabilidade que os brasileiros de fato perceberiam as semelhanças entre eles. Por exemplo, segundo mãe Viviana, foi durante uma festa no terreiro de Juquitiba que alguns de seus irmãos e parentes brasileiros perceberam, não sem espanto, que eles sabiam dançar e cantar

\footnotetext{
${ }^{20}$ Vale mencionar o interesse desses membros em aprender a língua portuguesa. Os filhos do terreiro da mãe Viviana, por exemplo, me pediram para preparar aulas de português. Por motivos organizativos, acabou não acontecendo.

${ }^{21}$ Os últimos dados do IBGE 2010 demonstram que somente $0,3 \%$ da população brasileira se identifica como pertencente às religiões afro-brasileiras, percentual que ficou invariável em relação ao censo de 2000. É evidente que esse número não representa a situação real dessas religiões e se apresenta abaixo da realidade por uma série de fatores, como demonstrou Prandi (2005).
} 
em yoruba ${ }^{22}$. As festas são de fato situações privilegiadas onde as "relações de ancestralidade são expressas e reforçadas" (FRIGERIO, 2013, p. 41), assim como a ideia de família e de codivisão de valores religiosos comuns.

Em relação às percepções de alguns brasileiros, os europeus são vistos como expressão de uma classe rica (FALDINI, 2009) e privilegiada. Embora essa percepção não corresponda à realidade: o fato de alguns desses europeus conseguirem comprar uma passagem aérea e realizarem uma viagem ao Brasil reforça a imagem e o estereótipo do "europeu rico". É importante notar que a maioria desses europeus pertencem à classe média e, no caso italiano, exercem funções ligadas à oferta de serviços, não sendo, portanto, possível afirmar que pertençam à uma elite econômica. Assim, a classe é utilizada pelos brasileiros para se construir diferenças entre os dois grupos e a distância entre eles estaria então ligada ao fato de pertencerem a classes sociais diferentes.

Um dos "privilégios" dos europeus estaria relacionado ao acesso ao conhecimento religioso, ou seja, os "estrangeiros" teriam a possibilidade de perguntar e de obter algumas informações, principalmente no período anterior à feitura. Enquanto aos abiãs brasileiros não seria permitido perguntar, já que o modo tradicional de aprendizado é através da observação e da frequentação do terreiro, os “estrangeiros” receberiam algumas explicações. Para alguns brasileiros, essa vantagem decorre da situação econômica privilegiada dos europeus. Na perspectiva de Pai Taunderan, os europeus teriam uma menor familiaridade com os rituais e os elementos religiosos do candomblé, religião considerada, de maneira geral, "distante da cultura deles" ou, na perspectiva de alguns italianos, "uma cultura que vem de fora"23. Além disso, no candomblé é previsto um

\footnotetext{
${ }^{22}$ Durante essa estadia, mãe Viviana estava acompanhada de dois filhos de santo seus, ambos italianos. Entrevista realizada em 13 jul. 2016, em Acilia, Roma, Itália.

23 Apesar do candomblé ser considerado "uma cultura que vem de fora" ou proveniente de um contexto distante, alguns europeus, em especial italianos, evocam uma proximidade geográfica da Europa em relação à África ao explicar os motivos de se pertencer ao candomblé. Afirmam que a Itália é mais perto da África que o Brasil e, além disso, se beneficiariam de trocas culturais e comerciais com o continente africano ao longo de vários séculos. Desse modo, cria-se uma ligação com o candomblé através da África, desnacionalizando-o, e que explicaria a pertença a essa religião. A África é mais uma vez evocada, embora de maneira diferente do caso argentino (FRIGERIO, 2013), que tem uma história e um passado colonial marcado pela escravidão e que, por isso, pode reivindicar uma herança cultural africana e afro-
} 
período de iniciação e de reclusão que, em alguns casos, gera dúvidas e perplexidades. A incorporação dos orixás também pode causar incertezas e medo, principalmente para quem experimenta o fenômeno em primeira pessoa. Essa diferença no comportamento, isto é, a necessidade de fazer perguntas, também foi apontada por alguns europeus, que afirmam precisar "saber tudo o que está acontecendo".

É importante ressaltar que as informações e as explicações fornecidas são de caráter geral e a importância do segredo, aspecto fundamental no candomblé, é sempre enfatizada. O cuidado de explicar, por exemplo, o porquê de se fazer determinado ritual ou realizar certa oferenda acaba facilitando a aproximação de pessoas que têm vontade de fazer o santo mas que, ao mesmo tempo, têm dúvidas por conhecerem pouco o candomblé e as religiões afro-brasileiras em geral. Essa preocupação de Pai Taunderan transmite segurança e se demonstra eficaz, considerando-se o número significativo de filhos de santo de outras nacionalidades que o pai de santo tem. Em suma, pode-se notar que ao centro dessas dinâmicas, explicitadas através das percepções que um grupo tem do outro, está o conhecimento religioso. As relações de proximidade e de distância são criadas a partir do acesso a esse conhecimento. Além de ser considerado o lugar de origem, os brasileiros teriam a seu favor a difusão do candomblé na sociedade em geral, o que não ocorre com os europeus. As percepções em relação a esses últimos revelam uma certa distância, seja em relação à classe social considerada diferente, seja, em algumas situações, em relação ao conhecimento mútuo, já que se afirma que alguns brasileiros desconhecem o candomblé feito na Europa. Essa distância pode diminuir ou desaparecer em momentos como as festas públicas, onde são enfatizadas a ideia de família e os valores

-americana. No caso italiano, se evoca uma proximidade geográfica que cria assim uma "fronteira" com a África permeável e marcada por trocas culturais e comerciais. Em certas circunstâncias, os portugueses também podem evocar o seu passado colonial e o continente africano. Em discursos que não dizem respeito às relações dentro da própria família de santo, mas que se referem a uma situação genérica no Brasil, evocam a raiz africana do candomblé, desnacionalizando-o, e as relações portuguesas com esse continente ligadas à uma herança pós-colonial (BAHIA, 2015) para se afirmar uma vocação própria portuguesa na preservação e na difusão do candomblé. Ao contrapor a realidade afro-portuguesa com uma situação brasileira na qual muitos terreiros teriam se tornado "turísticos", "comerciais", legitimam a própria prática e reivindicam um lugar de destaque no cenário afro-religioso. 
religiosos compartilhados. Entre os europeus, também há diferenças como, por exemplo, o conhecimento ou não da língua portuguesa, o que pode trazer certa vantagem. É importante ainda notar que as viagens que os europeus fazem ao Brasil e que podem, em alguns casos, serem marcadas por um aprendizado religioso feito no convívio e no cotidiano do terreiro brasileiro, são muito valorizadas, ainda que durem breves períodos. Desse modo, pode-se dizer que através dessas dinâmicas se reafirma o lugar onde a "fonte" e as raízes do candomblé está, ou seja, no Brasil.

\section{CONSIDERAÇÕES CONCLUSIVAS}

As dinâmicas relativas à expansão do candomblé e das religiões afro-brasileiras para outros países são frequentemente analisadas adotando-se o termo transnacionalização, entendido como o estudo dos processos de desalojamento e de localização de seus elementos culturais e religiosos em um novo contexto. É possível, no entanto, como nos lembra Frigerio (2013), conceituar a trasnacionalização como o estabelecimento de redes de relações que transcendem as fronteiras nacionais e que ligam pessoas que se encontram em países diferentes, utilizando-se, a esse fim, o conceito de campo social transnacional proposto por Levitt e Schiller (2004). Essa perspectiva atenta, sempre retomando Frigerio (2013), aos processos sincrônicos de como o campo é mantido, ou seja, aos processos que, em última análise, permitem a existência dessa comunidade - assim, a trasnacionalização é vista como um processo, ou processos, sempre em andamento.

Pensar a transnacionalização em termos relacionais nos ajuda a refletir sobre interações, experiências e percepções que aproximam ou distanciam membros que fazem parte de uma mesma linhagem religiosa e que, mesmo morando longe, graças a essa estrutura entram, ou podem entrar, em contato. Desse modo, nos permite tencionar proximidades e distâncias, reais e imaginárias, geográficas, econômicas, que unem e que separam esses membros e esses contextos. 
Ao adotar essa perspectiva e assim focalizar as relações dentro da linhagem religiosa, podemos notar a circulação e a direção dos fluxos econômico, de conhecimento religioso, de bens materiais e simbólicos que caracterizam essas interações e que fazem possível a existência de comunidades de candomblé em outros países. A circulação e a direção dos fluxos não são casuais ou pré-estabelecidas, mas podem variar de acordo com a situação, revelando dinâmicas e estratégias, pessoais ou coletivas para, por exemplo, manter ou fundar um terreiro em um novo contexto. Além disso, o conceito de campo social transnacional nos permite pensar as diferentes maneiras de participar e de ser influenciado por esse, modos que podem variar dependendo do momento ou do contexto. Dessa forma, considera-se as experiências dos outros participantes que, mesmo não sendo agentes nodais, compõem e agem no campo se algum acontecimento ou o contexto os levar a tal. Esse é um aspecto importante e que precisa ser ainda aprofundado para se compreender melhor a multiplicidade das experiências que acontecem para além das próprias fronteiras nacionais. Nesse caso, os usos que os membros do campo fazem da internet e das redes sociais merecem lugar de destaque, já que agilizam o contato entre eles e permitem conexões e contatos mais amplos, fora da família ou da linhagem religiosa, em particular com o universo geral das religiões de matriz africana.

É importante observar ainda as percepções mútuas que decorrem das situações de convivência e de sociabilidade. Como vimos, as relações de proximidade e de distância entre eles são construídas a partir do acesso ao conhecimento religioso, revelando também as tentativas de reafirmação do lugar de origem e das raízes dessas práticas. De fato, considerando as duas abordagens, tanto em termos de fluxos quanto de percepções, é possível observar como o saber religioso e a sua transmissão atravessam as várias dinâmicas relacionais e se repropõem em contextos transnacionais. É preciso então levá-los em consideração, afinal, como nos lembra Dias (2014, p. 14), "a religião é um produto cultural que se transmite e se aprende/apreende" e a situação transnacional pode assim acrescentar novas questões. Vimos como o cuidado e a adaptação nos modos de transmissão de parte do conhecimento, 
ao fornecer algumas explicações e informações antes da iniciação, facilitaram a aproximação e tranquilizaram potenciais filhos de santo provenientes de outros países, o que produz também efeitos na maneira de se relacionar com o próprio filho de santo.

É evidente que as relações e os contatos entre os membros de uma mesma linhagem podem variar ao longo dos anos, aumentar ou tendencialmente diminuir a medida em que se obtém maior autonomia. O que se apresenta aqui é uma fotografia de processos sempre em curso. Se, por um lado, isso dificulta a proposição de conclusões, por outro, nos mostra a complexidade e a necessidade de observar a transnacionalização dessas religiões nos seus mais variados aspectos.

\section{REFERÊNCIAS BIBLIOGRÁFICAS}

1. ALVES, Daniel. Aportes teórico-metodológicos para o estudo de redes transnacionais de líderes pentecostais e carismáticos. Revista Horizontes Antropológicos, Porto Alegre, v. 18, n. 37, p. 45-71, 2012.

2. APPADURAI, Arjun. Modernità in polvere. Roma: Raffaello Cortina, 2012.

3. ARAKAKI, Ushi. Japanese brazilians among Pretos-Velhos, Caboclos, Buddhist monks, and Samurais: an ethnographic study of Umbanda in Japan. In: ROCHA, Cristina; VÁSQUEZ, Manuel (org.). The Diaspora of Brazilian Religions. Boston: Brill, 2013, p. 249-270.

4. ARGYRIADIS, Kali; CAPONE, Stefania; DE LA TORRE, Renée; MARY, Andre (org.). Religions transnationales des suds: Afrique, Europe, Amériques. Louvainla-Neuve: Academia, 2013.

5. ARGYRIADIS, Kali; DE LA TORRE, Renée. Présentation générale et méthodologie: les défis de la mobilité. In: ARGYRIADIS et al. Religions transnationales des suds: Afrique, Europe, Amériques. Louvain-la-Neuve: Academia, 2013, p. 13-25.

6. AUGÉ, Marc. Per un'antropologia della mobilità. 2. ed. Milão: Jaca Book, 2015.

7. BAHIA, Joana. As religiões afro-brasileiras em terras alemãs e suíças. ICS Working Papers, Lisboa, p. 02-21, 2013. 
8. BAHIA, Joana. Exu na mouraria: a transnacionalização das religiões afro-brasileiras e suas adaptações, trocas e proximidades com o contexto português. MÉTIS: história e cultura, Caxias do Sul, v. 14, n. 28, p. 111-131, 2015.

9. BEM, Daniel Francisco. A preponderância das fronteiras geográfica e simbólica na transnacionalização afro-religiosa no Prata. Debates do NER, Porto Alegre, ano 9, n. 13, p. 25-46, 2008.

10. BOURDIEU, Pierre. Sul concetto di campo in sociologia. Roma: Armando Editore, 2010.

11. CAPONE, Stefania. A propos des notions de globalisation et de transnationalisation. Civilisations, Paris, v. 51, p. 9-22, 2004.

12. CASTILLO, Lisa Earl. Entre a oralidade e a escrita: a etnografia nos candomblés da Bahia. Salvador: EDUFBA, 2008.

13. DIAS, João Ferreira. À cabeça carrego a identidade: o orí como um problema de pluralidade teológica. Afro-Ásia, Salvador, n. 49, p. 11-39, 2014.

14. FALDINI, Luisa. Biylu: è nato per la vita: Creazione dello spazio e della persona in un candomblé di Juquitiba (Brasile). Roma: CISU, 2009.

15. FRIGERIO, Alejandro. A transnacionalização como fluxo religioso na fronteira e como campo social: umbanda e batuque na Argentina. Debates do NER, Porto Alegre, ano 14, n. 23, p. 15-57, 2013.

16. GOLFETTO, Tatiana. Il candomblé keto in Italia: storia, flussi, adattamenti. 2017. Tese (Doutorado em História, Antropologia, Religiões) - Sapienza Universitá di Roma, Roma, 2017.

17. HANNERZ, Ulf. Fluxos, fronteiras, híbridos: palavras-chave da antropologia transnacional. Mana, Rio de Janeiro, v. 3, n. 1, p. 7-39, 1997. Disponível em: http:// bit.ly/2uAsWYK. Acesso em: 13 nov. 2019.

18. HANNERZ, Ulf. La diversità culturale. Bologna: Il Mulino, 2001.

19. IBGE. Censo demográfico 2010: características gerais da população, religião e pessoas com deficiência. Rio de Janeiro: IBGE, 2012. Disponível em: http://bit. ly/2IjHCil. Acesso em: 05 mar. 2020.

20. LEVITT, Peggy; SCHILlER, Nina Glick. Conceptualizing Simultaneity: a transnational social field perspective on society. International Migration Review, Nova York, v. 38, n. 3, p. 1002-1039, 2004.

21. PORDEUS JR., Ismael. Portugal em transe: transnacionalização das religiões afro-brasileiras. Lisboa: Imprensa de Ciências Sociais, 2009.

22. PRANDI, José Reginaldo. Os candomblés de São Paulo: a velha magia na metrópole nova. São Paulo: Hucitec: Edusp, 1991. 
23. PRANDI, Reginaldo. Segredos guardados: orixás na alma brasileira. São Paulo: Companhia das Letras, 2005.

24. ROBERTSON, Roland. Globalizzazione: teoria sociale e cultura globale. Trieste: Asterios, 1992.

25. ROCHA, Cristina; VÁSQUEZ, Manuel (org.). The diaspora of brazilian religions. Boston: Brill, 2013.

26. TEISENHOFFER, Viola. Umbanda, New Age et psychothérapie: aspects de l'implantation de l'umbanda à Paris. Ateliers du LESC, Paris, n. 31, 2007. Disponível em: http://bit.ly/2T2FMZg. Acesso em: 13 nov. 2019.

27. VALLADO, Armando. Lei-do-santo: poder e conflito no candomblé. Rio de Janeiro: Pallas, 2010.

28. VERENI, Piero. Le modernità di tutti: il contributo di Arjun Appadurai al dibattito sulla globalizzazione. In: APPADURAI, Arjun. Modernità in polvere. Roma: Raffaello Cortina, 2012. p. VII-XLI. 